Available online at www.sciencedirect.com

\title{
Studies of the RNA Degradosome-organizing Domain of the Escherichia coli Ribonuclease RNase E
}

\author{
Anastasia J. Callaghan', Jukka P. Aurikko', Leopold L. Ilag² \\ J. Günter Grossmann ${ }^{3}$, Vidya Chandran ${ }^{1}$, Karin Kühnel ${ }^{1}$ \\ Leonora Poljak ${ }^{4}$, Agamennon J. Carpousis ${ }^{4}$, Carol V. Robinson ${ }^{2}$ \\ Martyn F. Symmons ${ }^{1}$ and Ben F. Luisi ${ }^{1 *}$
}

\author{
${ }^{1}$ Department of Biochemistry \\ University of Cambridge, 80 \\ Tennis Court Road, Cambridge \\ CB2 1GA, UK \\ ${ }^{2}$ Department of Chemistry \\ University of Cambridge \\ Lensfield Road, Cambridge CB2 \\ $1 E W$, UK

\section{${ }^{3}$ Synchrotron Radiation} \\ Department, CCLRC \\ Daresbury Laboratory \\ Daresbury, Warrington WA4 \\ $4 A D, U K$ \\ ${ }^{4}$ Laboratoire de Microbiologie et \\ Génétique Moléculaire, Centre \\ National de la Recherche \\ Scientifique, UMR 5100, 118 \\ Route de Narbonne, 31062 \\ Toulouse Cedex, France
}

\begin{abstract}
The hydrolytic endoribonuclease RNase E, which is widely distributed in bacteria and plants, plays key roles in mRNA degradation and RNA processing in Escherichia coli. The enzymatic activity of RNase E is contained within the conserved amino-terminal half of the $118 \mathrm{kDa}$ protein, and the carboxy-terminal half organizes the RNA degradosome, a multi-enzyme complex that degrades mRNA co-operatively and processes ribosomal and other RNA. The study described herein demonstrates that the carboxy-terminal domain of RNase E has little structure under native conditions and is unlikely to be extensively folded within the degradosome. However, three isolated segments of 10-40 residues, and a larger fourth segment of 80 residues, are predicted to be regions of increased structural propensity. The larger of these segments appears to be a protein-RNA interaction site while the other segments possibly correspond to sites of self-recognition and interaction with the other degradosome proteins. The carboxy-terminal domain of RNase E may thus act as a flexible tether of the degradosome components. The implications of these and other observations for the organization of the RNA degradosome are discussed.
\end{abstract}

(C) 2004 Elsevier Ltd. All rights reserved. unstructured proteins; RNA processing; ribonuclease E

Present address: K. Kühnel, Department of Biomolecular Mechanisms, Max-Planck-Institute for Medical Research, Jahnstrasse 29, D-69120 Heidelberg, Germany.

Abbreviations used: CD, circular dichroism; CTD, carboxy-terminal domain; NTD, amino-terminal domain; R-domain, a sub-domain of the CTD, corresponding to residues 628-843; DMS, dimethyl suberimidate; PNPase, polynucleotide phosphorylase; RNase, E, ribonuclease E; RhlB, the ATP-dependent RNA helicase of the RNA degradosome; IUP, intrinsically unstructured protein; MALDI-TOF MS, matrix-assisted laser desorption/ ionization time-of-flight mass spectrometry; MS/MS, tandem mass spectrometry; RISP, region of increased structural propensity.

E-mail address of the corresponding author: ben@cryst.bioc.cam.ac.uk

\section{Introduction}

Escherichia coli possesses at least five endoribonucleases which all operate under tight cellular regulation and are involved in the modification, maturation and degradation of ribonucleic acids. ${ }^{1}$ One of these endoribonucleases, RNase E, is essential for cell viability, ${ }^{2,3}$ and amongst its important roles is the processing of transfer RNA, $9 \mathrm{~S}$ ribosomal RNA, the catalytic RNA of RNase P, and the transfer/messenger RNA (tmRNA) that rescues stalled ribosomes. ${ }^{4-6}$ Most prominent, however, is the function of RNase E in general mRNA decay. In E. coli, RNase $\mathrm{E}$ has been shown to control the levels of many different transcripts that encode enzymes of fundamental metabolic pathways, including glycolysis. ${ }^{8}$ And amongst the transcripts targeted by RNase $\mathrm{E}$ is its own mRNA, with the 
consequence that the enzyme level is autoregulated.9,10 RNase E has also recently been shown to be involved in the degradation pathway of small regulatory RNAs. ${ }^{11}$

E. coli RNase E is 1061 amino acid residues in length and is one of the larger proteins in this organism. ${ }^{12,13}$ The protein can be divided into two roughly equal portions, referred to here as the $\mathrm{N}$ terminal domain (NTD; residues 1-498) and the C-terminal domain (CTD; residues 499-1061), and each has a different function ${ }^{14,15}$ (Figure 1A). The NTD has numerous homologues, most notably the paralogue RNase $G$ encoded by the $r n g$ gene $^{16}$ (Figure 1A). In contrast, the CTD of RNase E has much fewer homologues and even these have little apparent conservation of primary structure. ${ }^{17}$ The catalytic function of RNase $\mathrm{E}$ resides entirely within the conserved $\mathrm{NTD}^{18}$ and no catalytic activity has been observed for the more variable CTD. Both the NTD and CTD have an argininerich segment, corresponding to residues 267-390 in the $\mathrm{NTD}^{17}$ and to residues $600-684$ in the CTD. ${ }^{18,19}$ These arginine-rich domains are likely to interact with RNA, although the latter is not required for catalytic activity. ${ }^{20}$

RNase E has a preference for A/U-rich substrates, but cannot cleave RNA substrates at sites that are well-structured, such as stem-loops. However, in E. coli the activity of RNase E may be facilitated by its association with other RNA-processing enzymes in the multi-component RNA degradosome complex. ${ }^{21-23}$ The principal components of this complex consist of polynucleotide phosphorylase (PNPase), an ATP-dependent helicase (RhlB)

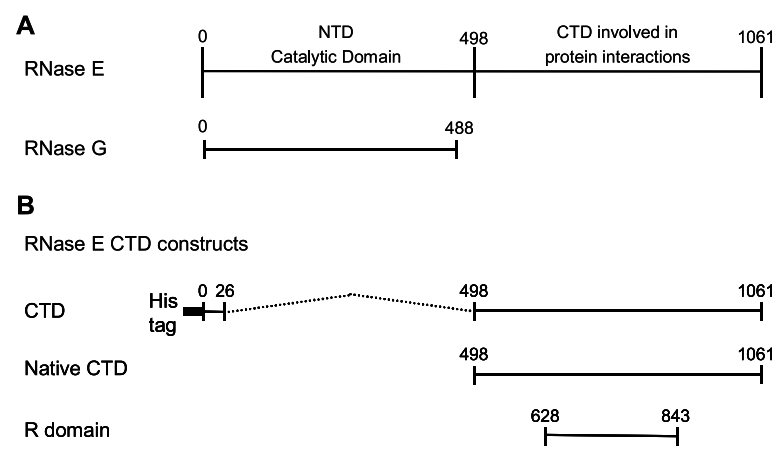

Figure 1. Domain structure of E.coli RNase E and expression constructs. A, A schematic of RNase E, showing the boundaries for the catalytic $\mathrm{N}$-terminal domain (NTD) and the degradosome scaffolding C-terminal domain (CTD). The NTD has sequence similarity with the paralogue RNase $G$, which is also included in the illustration. B, A schematic representation of the CTD proteins used in this study: CTD refers to the protein product of the His-tagged construct used for expression and purification of RNase E CTD. Native-CTD is the theoretical protein product of the construct used for expression and co-purification of RNase E CTD with enolase. The protein product of the R-domain construct is also shown. A histidine-tagged version of the Rdomain was also prepared for the electrophoretic mobility assay shown in Figure 5C. and the glycolytic enzyme enolase. ${ }^{22,24}$ Also, several other degradosome-associated proteins have been discovered that occur as minor components, including polyphosphate kinase (PPK) and the chaperones GroEL and DnaK. ${ }^{23,25}$

The Protein Families database (Pfam, Sanger Institute) does not identify any known folds within the CTD domain and indicates that this portion of RNase E has low sequence complexity, which is a characteristic of unstructured proteins. ${ }^{26}$ A composition analysis presented here predicts that the CTD is predominantly unstructured, and this is consistent with our observations from solution Xray scattering, limited protease digestion and circular dichroism. The data also indicate that the domain is unlikely to fold extensively upon interaction with the other degradosome components. We identified four small segments ranging from ten to 80 residues that are predicted to be regions of increased structural propensity (RISP), and we propose that these segments may mediate interactions with RNA or the degradosome proteins helicase RhlB, PNPase or enolase, or self-interaction. We characterize the interactions of two of these segments with enolase and polynucleotide phosphorylase. The implications of these and other observations for the organization of the RNA degradosome are discussed.

\section{Results}

\section{Purification and characterization of the $E$. coli RNase E C-terminal domain (CTD)}

The CTD (corresponding to the top schematic drawing, Figure 1B) expressed well in E. coli host strains, but was highly unstable once the cells were lysed. We therefore isolated the protein to homogeneity under denaturing conditions and optimised the refolding conditions. The predicted weight of the CTD is $67.7 \mathrm{kDa}$, but the purified protein runs closer to $90 \mathrm{kDa}$ by SDS-PAGE. As will be shown below, the refolded protein was active, as seen by its ability to oligomerize, to bind helicase RhlB and to recognize structured RNA.

The refolded isolated CTD was analysed by solution X-ray scattering. Figure 2A shows its scattering profile and, for comparison, the profile of NTD, which is known to be globular. ${ }^{27}$ The scattering profile for the CTD has the characteristics of less well-folded proteins, such as the asymptotic behaviour of the Kratky plot (Figure 2A, green profile in the inset) that is characteristic of random chains. ${ }^{28}$ In contrast, the Kratky plot for the NTD (Figure 2A, red profile in the inset) lacks these features. Nonetheless, the CTD may have some residual structure, which can explain the observed maximum at approximately $0.01 \AA^{-1}$ in the Kratky plot. ${ }^{29}$ Structural parameters calculated from the scattering data for the CTD are $R_{\mathrm{g}}=147.2( \pm 2) \AA$ and $D_{\operatorname{MAX}}=430( \pm 20) \AA$. In comparison, the values for the NTD are $R_{\mathrm{g}}=51.0( \pm 0.3) \AA$ and 


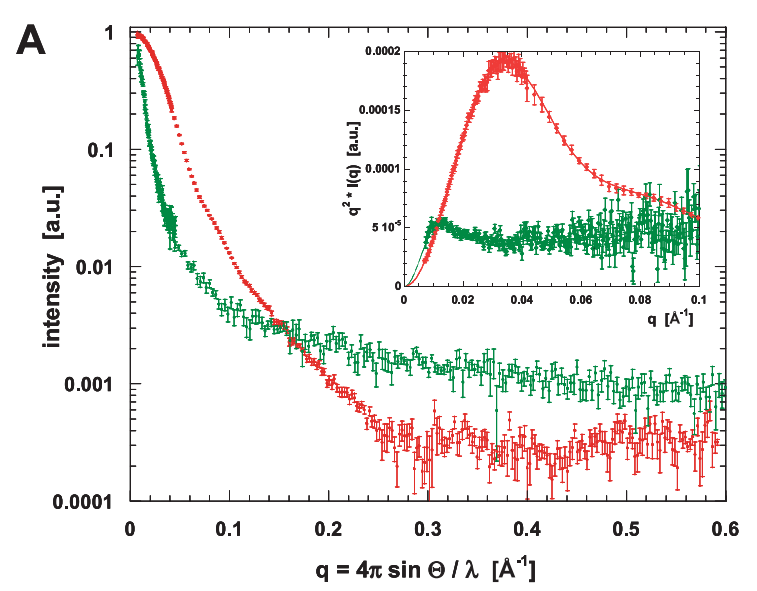

B

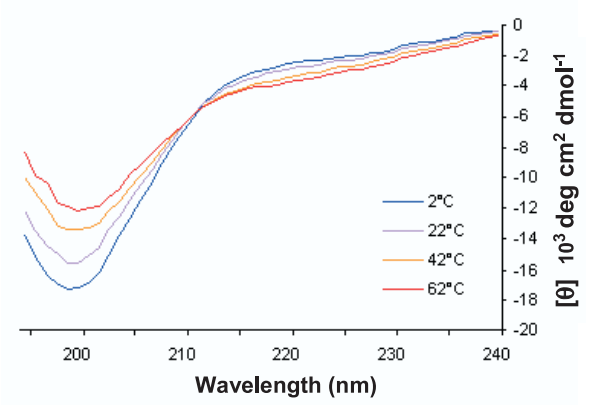

Figure 2. The CTD has partial structure. A, A comparison of the normalised X-ray scattering profiles of the NTD (red) and the CTD (green). A Kratky plot is shown in the inset. The momentum transfer $q$ is defined by the scattering angle $2 \theta$ and the wavelength $\lambda=1.54 \AA$. $B$, Circular dichroism spectrum of the CTD at different temperatures.

$D_{\text {MAX }}=160( \pm 5) \AA$. The observed $D_{\text {MAX value of the }}$ CTD is indicative of residual structure, as a completely extended protein of 610 residues would have a $D_{\text {MAx }}$ value of $2191 \AA$ (calculated by the equation $D_{M A X}=n l_{\mathrm{o}} f$, where $n=$ number of residues, $l_{\mathrm{o}}=$ distance between two adjacent $\alpha$-carbon atoms $(3.78 \AA$ ) and $f=$ bond angle geometric factor; for a random coil this is set at 0.95)..$^{30,31}$

Circular dichroism (CD) was used to evaluate the structural characteristics of the refolded CTD (Figure 2B). The CD spectra display the characteristics of a partly unstructured protein: a large negative peak at $200 \mathrm{~nm}$ and a value close to zero at $220 \mathrm{~nm}$. A temperature-melt experiment indicated a loss of CD spectral signal at $200 \mathrm{~nm}$, suggesting that some secondary structural elements are present. In agreement with the solution scattering observations, these spectroscopic data suggest that the CTD is only partly structured.

\section{Protein-protein and protein-RNA interactions of RNase E CTD}

As mentioned above, the CTD was purified under denaturing conditions and refolded. To confirm that the refolded material was functionally active, we tested for its interactions with the other
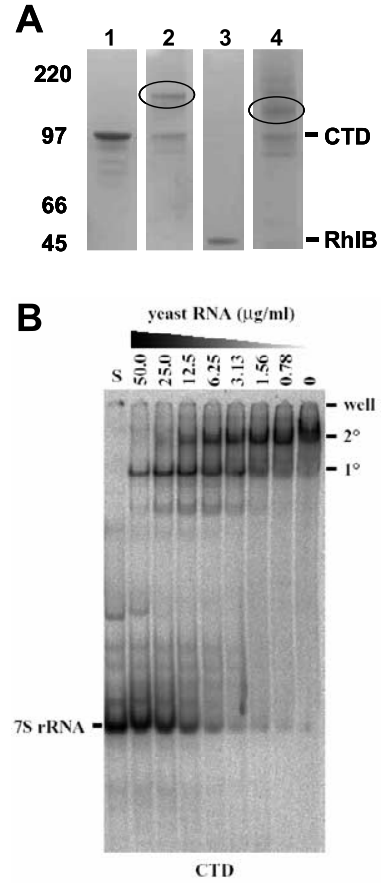

Figure 3. Interactions of refolded CTD with protein and RNA. A, Chemical cross-linking of the CTD. SDSPAGE analysis of renatured CTD in the absence of DMS (lane 1) and the presence of the reagent (lane 2). The circled band corresponds to a homodimer of the CTD. Lane 3 shows the purified helicase RhlB (the same profile was observed for the helicase RhlB in the absence and presence of DMS). Lane 4 shows the DMS-treated mixture of helicase and CTD. The circled band was shown to contain both helicase RhlB and CTD using in-gel protease digestion and MALDI-mass spectrometry analysis. B, Electrophoretic mobility, shift assay of refolded CTD with RNA. Native PAGE analysis of renatured CTD incubated with $7 \mathrm{~S}$ rRNA and increasing amounts of competitor yeast RNA. Lane $\mathrm{S}$ is the 7S rRNA alone. The increasing concentrations of yeast RNA (in $\mu \mathrm{g} / \mathrm{ml}$ ) are shown schematically by the triangle above the gel and the numeric values are given at the top of each lane. The $7 \mathrm{~S}$ rRNA and band-shifted species are labelled.

degradosome components and with structured RNA. Protein-protein interactions were tested using the chemical cross-linking agent dimethyl suberimidate (DMS) (Figure 3A). Using denaturing gels, a cross-linked complex was observed with helicase (Figure 3A, lane 4). RhlB alone does not self-associate (as confirmed in this study by nanoflow mass spectrometry; see below) and was not cross-linked by DMS. The helicase RhlB-CTD cross-linked species was analysed by in-gel digestion with protease and the peptide fragments identified using mass spectrometry, confirming the presence of both proteins. New, cross-linked digest species of the two proteins were also observed that were not present in the control digest samples of the two isolated proteins alone. The CTD was also observed to self-associate (Figure 3A, lane 2).

The refolded CTD was also tested for RNA binding by an electrophoretic mobility-shift assay. It was observed to bind to $7 \mathrm{~S}$ rRNA with high 
affinity forming two well-defined complexes (Figure 3B). A 30-fold excess by weight of yeast RNA $(50 \mu \mathrm{g} / \mathrm{ml})$ was sufficient for nearly complete competition with the $7 \mathrm{~S}$ rRNA. The first complex $\left(1^{\circ}\right)$ diminishes as the concentration of competitor yeast RNA decreases, while the second complex $\left(2^{\circ}\right)$ becomes stronger. This suggests that the first complex binds more strongly than the secondary complex. Other experiments (not shown) suggest that the dissociation constant of the $1^{\circ}$ complex is in the range of $0.1-1 \mathrm{nM}$.

\section{Identification of segments of structural propensity within the CTD}

The amino acid sequence of the full-length RNase E was analysed using two programs that predict the propensity for disorder within a protein sequence. The GlobPlot ${ }^{32}$ algorithm is based on correlation of amino acid composition with ordered or disordered states. This program showed the RNase E NTD to be predominantly structured/ globular, whereas the CTD has a significantly greater propensity for being disordered. Similar results were obtained with the Predictors of Natural Disordered Regions (PONDR $\left.{ }^{\circledR}\right)$ program, which uses averaged physical-chemical properties of amino acid residues, hydropathy and sequence complexity to predict unstructured regions. ${ }^{33-37}$ As shown in Figure 4A, the NTD is predicted to be structured, whereas the CTD, in striking contrast, has characteristics of predominantly unstructured proteins. For most of the CTD, the scores are above the threshold value of 0.5 , indicating unstructured domains (indicated by the bold black line; Figure 4A). The CTD is highly enriched in Arg, Pro, Gly and Glu residues, as shown in Figure $4 \mathrm{~B}$, and this is in accord with the predicted limited structural content. However, there are three isolated segments that are predicted to be regions of increased structural propensity (RISPs). These correspond to residues 565-585, 839-850, and 10211061. We refer to these segments as A, C and D respectively, as shown in Figure 4A. A segment of coiled coil is strongly predicted by the COILS program $^{38}$ for residues 633-662 and 685-712 (Figure 4C), which also corresponds to a sharp deviation in the profile within the disorder region identified by the PONDR ${ }^{\circledR}$ program, and is labelled B (Figure 4A). Segment B encompasses the Argrich RNA-binding domain ${ }^{18,39}$ and we propose that it is the coiled-coil region that interacts with RNA. The apparent predominant lack of structure, punctuated by small RISPs, is in accord with the solution scattering and circular dichroism observations described here.

\section{R-domain interactions with helicase and RNA}

The R-domain was used in earlier studies ${ }^{19}$ and was prepared because of its convenient cloning sites. This region (residues 628-843) corresponds to a $28 \mathrm{kDa}$ segment of the CTD (Figure 1B). It runs at approximately $40 \mathrm{kDa}$ on SDS-PAGE. The $\mathrm{R}$-domain encompasses the region predicted to be a coiled coil (segment B) and part of segment C that is predicted to be structured (Figure 4). Purified helicase RhlB binds avidly to this domain, and the R-domain-helicase complex can be isolated by size-exclusion chromatography as an earlier-eluting species in an approximate $1: 1$ stoichiometric complex (Figure 5A, Lane 1). We also tested whether enolase could be recruited into the helicase RhlB-R-domain complex, but we could not observe any association by native gel or size-exclusion chromatography (Figure 5A, lane 2 ). In comparison with the ATPase activity of the isolated helicase, the purified helicase RhlB-Rdomain complex is 25-fold more active. This suggests that the protein-protein interaction is stimulatory, in agreement with the findings reported by Vanzo et al. ${ }^{19}$ Limited protease digestion shows that the highly basic C-terminal $2 \mathrm{kDa}$ fragment of the helicase is readily cleaved by trypsin (residues 403-420, confirmed by mass spectrometry analysis) and that the core of the protein is comparatively more resistant to further digestion (results not shown). This C-terminally truncated helicase RhlB was also found to form a stable complex with the R-domain (Figure 5B) in an approximate 1:1 stoichiometry (Figure 5B inset), indicating that the highly basic tail is not required for this protein-protein interaction.

Confirmation of the stoichiometric ratio of $\mathrm{R}$ domain to helicase RhlB came from nanoflow-ES mass spectrometry (Figure 6). ${ }^{40}$ The spectrum of helicase RhlB alone reveals a charge state series corresponding to the monomeric form of the protein, with an observed mass of $46,999( \pm 3) \mathrm{Da}$ (theoretical mass of 46,995 Da) (Figure 6A, black trace). A low-intensity series assigned to a dimer was also identified but this was not observed after dilution, suggesting it to be a non-specific interaction. Upon addition of R-domain to the helicase RhlB in a 1:1 ratio, three charge state series can be discerned (Figure 6A, red trace). The predominant species represented by series A corresponds to the helicase RhlB monomer (Figure 6A, series A). Series $\mathrm{B}$ corresponds to the R-domain with a measured mass of $29,044( \pm 41) \mathrm{Da}$ (theoretical mass of $28,822 \mathrm{Da})$ and the charge state series $\mathrm{C}$ with a mass of $76,763( \pm 13) \mathrm{Da}$ corresponds to one R-domain bound to one helicase RhlB (theoretical mass $75,817 \mathrm{Da}$ ) (Figure 6A). The additional mass observed can be attributed to the binding of water/ buffer ions, which is observed typically in mass spectrometric analysis of protein complexes. Tandem mass spectrometry (MS/MS) of the complex ion $(C+19)$ confirmed the composition of the species to be that of R-domain and helicase RhlB (Figure 6B).

Circular dichroism indicates that the R-domain is predominantly unstructured and that the Rdomain-helicase RhlB complex has the same secondary structural composition as the helicase RhlB alone. Thus, it seems that the R-domain does not undergo appreciable folding on interaction with 
A

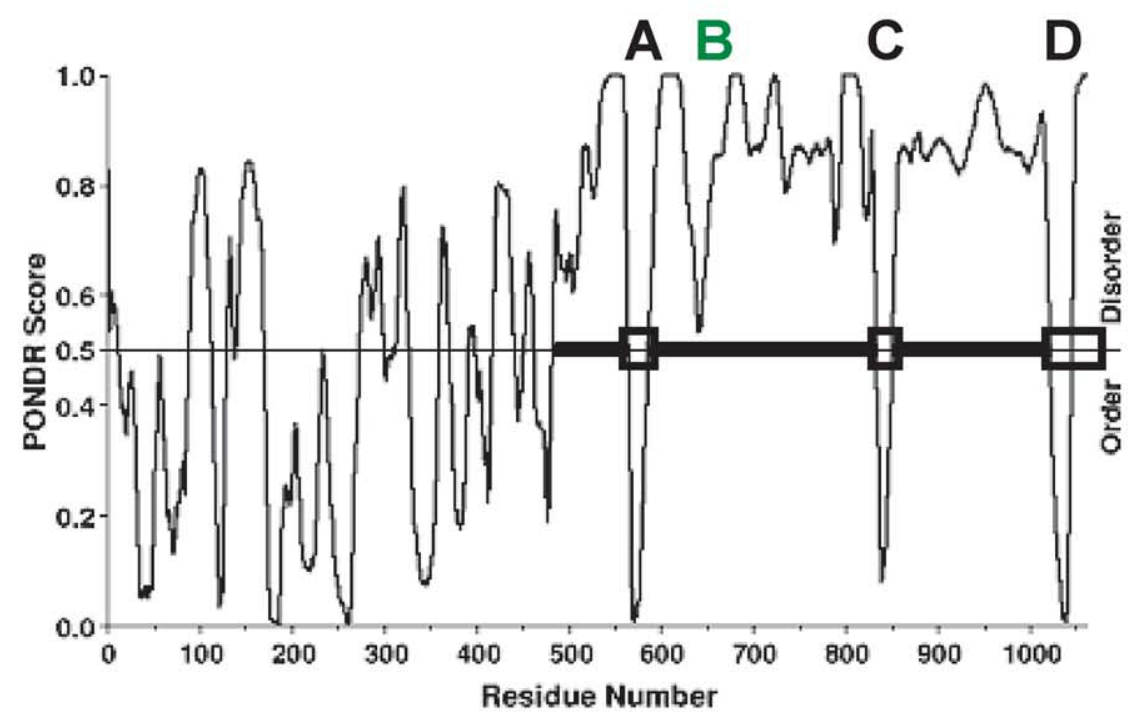

B
500 YMLPKLHEEAMALPSEEEFAERKREEOPALATFAMPDVPPAPTPAEPAAPVVAPAPKAAPATPAA
A 565 PAQPGLLSRFFGALKALF SGGEETKPTEEPAPKAEAKPERQQDRRKPRQNNRRDRNERRDTRSER
B 630 TEESDNREENRRNRRQAQQQTAETRESRQQAEVTEKARTADEQOAPRRERSRRRNDDKRQAQOEA
695 KALNVEEQSVEETEQEER VRVVQPRRKQRQRLNQKVRY YE ESVAEEAVVAPVVEETVAAEPIVQEᄑP
760 APRTELLVKVPLPVVAQTAPEQQEENNADNRDNGGMPRRSRRSPRHLRVSGQRRRRYRDERYPTQS
C 825 PMPLTVACR SPELASGKVWIRYPIVRPPDVQVEEQREOEEVHVQPMVTEVVPVAAIEPVVSAPVV

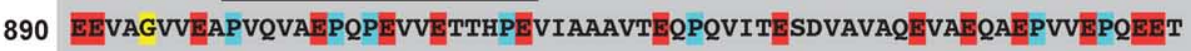

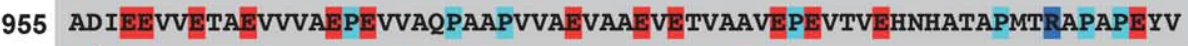
D 1020 PEAPRHSDWQRPTFAFEGKGAAGGHTATHHASAAPARPQPVE

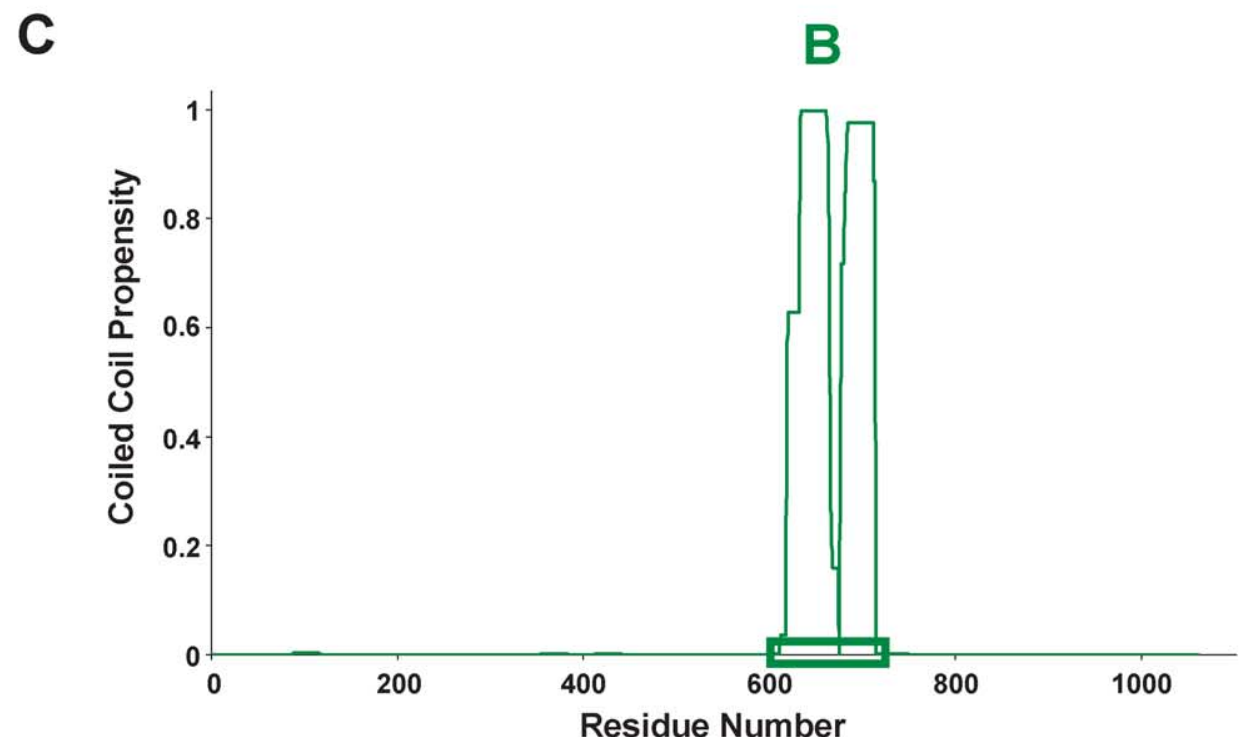

Figure 4. Predictions of RISPs in the E. coli CTD. A, PONDR ${ }^{\circledR}$ analysis of RNase E. Unstructured segments have scores greater than 0.5 (horizontal line). B, The primary sequence of E. coli RNase E CTD (residues 500-1061). Proline residues (cyan), arginine residues (blue), glycine residues (yellow) and glutamic acid (red) are highlighted to emphasize their enrichment in the sequence. The sequence was formatted using CHROMA. ${ }^{58}$ The segments that deviate in the PONDR ${ }^{\circledast}$ profile are boxed in black and the region predicted to be coiled-coil (see C) is boxed in green. C, Potential coiled-coil regions in the CTD, predicted using the COILS program. ${ }^{38}$ 


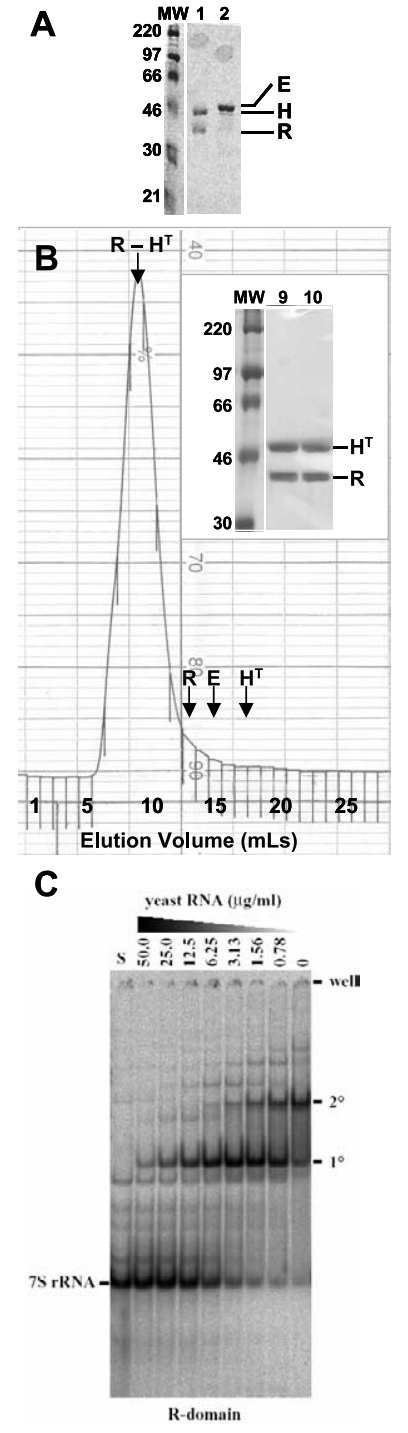

Figure 5. The interaction of R-domain with intact and truncated helicase RhlB, enolase, and RNA. A, SDSPAGE analysis of fractions eluted from size-exclusion chromatography for a mixture of R-domain (R), intact helicase RhlB $(\mathrm{H})$ and enolase (E). Lane 1 corresponds to the first peak, identified as a complex of R-domain and helicase RhlB. Lane 2 corresponds to the second peak eluted and contains enolase alone. Molecular mass markers are indicated by MW. B, Elution profile from size-exclusion chromatography for a complex of Rdomain and truncated (trypsin treated) helicase RhlB $\left(\mathrm{R}-\mathrm{H}^{\mathrm{T}}\right)$. Positions at which the truncated helicase RhlB $\left(\mathrm{H}^{\mathrm{T}}\right), \mathrm{R}$-domain $(\mathrm{R})$ and enolase $(\mathrm{E})$ alone elute are indicated on the trace. (B inset) SDS-PAGE analysis of the Rdomain-truncated helicase RhlB complex fraction eluted from the column. Lanes 9 and 10 correspond to the fractions eluted at $9 \mathrm{ml}$ and $10 \mathrm{ml}$ elution volume as shown on the elution profile, and indicates that both proteins are present in roughly stoichiometric ratio. C, Electrophoretic mobility-shift assay of refolded R-domain with $7 \mathrm{~S}$ rRNA. Details are as for Figure 3B, except that here $\mathrm{R}$-domain is substituted for CTD.

the helicase, despite the apparent avidity of the complex. In this regard we also note that the complex elutes aberrantly in size-exclusion chromato-
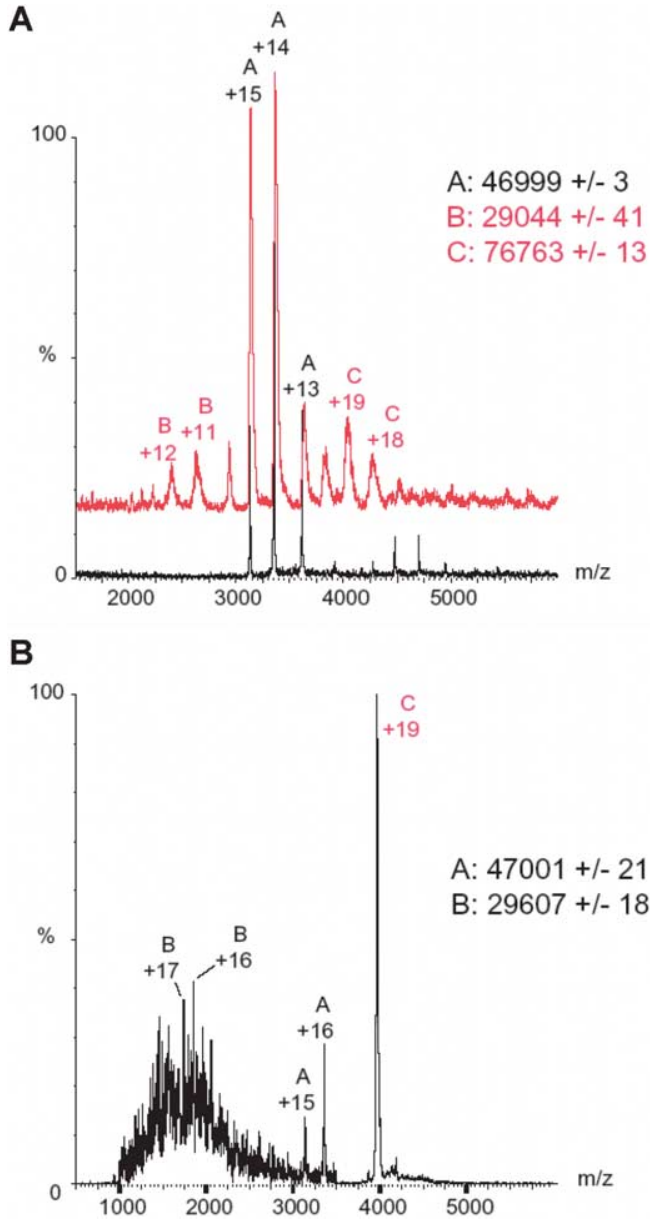

Figure 6. Nanoflow-ESI mass spectra of R-domain and helicase RhlB recorded under non-dissociating conditions. A, ESI mass spectrum of helicase RhlB (black trace) and a mixture of R-domain and helicase RhlB (red trace), vertically offset from 0 for clarity. Charge state series $\mathrm{A}$ is assigned to helicase RhlB monomer. Two sets of minor series: B corresponding to R-domain and C corresponding to a $1: 1$ stoichiometric complex of R-domain and helicase RhlB are also observed. B, MS/MS analysis of R-domain-helicase RhlB complex $C+19$ ion. Series A corresponds to helicase RhlB monomer whereas series B corresponds to R-domain. The range $m / z 1000-3000$ is magnified $10 \times$ for clarity.

graphy (>500 kDa) and is well in excess of its predicted mass of $74 \mathrm{kDa}$, which further suggests that it has a largely unstructured portion.

The ability of R-domain to bind to structured RNA was tested by electrophoretic mobility-shift assays. Like the CTD, shown in Figure 3B, the Rdomain was also observed to form two complexes with $7 \mathrm{~S}$ rRNA (Figure 5C). The $1^{\circ}$ complex forms even in the presence of a five- to tenfold excess of competitor yeast RNA.

\section{Co-purification of the C-terminal domain with enolase}

A version of the CTD without affinity tags was overexpressed in E. coli and isolated under native, 
rather than denaturing, conditions (corresponding to residues 498-1061). We developed a rapid purification protocol with protease inhibitors to overcome problems with degradation of the protein. We refer to this version as native-CTD (Figure 1B). Throughout the purification, the native-CTD copurified with a protein of roughly $45 \mathrm{kDa}$ molecular mass. Amino-terminal sequencing revealed this to be enolase. Sequence analysis also showed that the native-CTD had lost the first 82 residues at the amino terminus. In-gel protease digestion gave evidence for fragments up to residue 1038, but no further, so native-CTD was therefore thought to consist of residues 580 to roughly 1038 .

In subsequent purification of the native-CTD, purified enolase was included in the cell lysate. The native-CTD-enolase complex eluted from a S200 gel-filtration column as a single peak and was identified as one species on a native gel (Figure 7A). The peak was observed to contain both components when analysed by SDS-PAGE

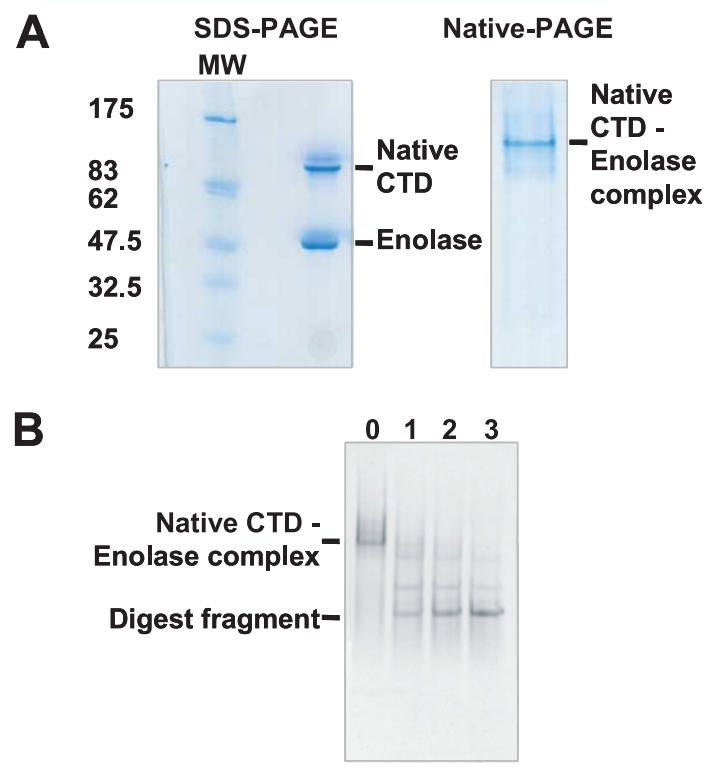

\section{C \\ $\mathrm{N}$-terminal sequencing of digest fragment \\ Enolase - ' ${ }^{\text {SKIVKIIGRE }}$ \\ Native CTD $-{ }^{816}$ RDERYPTQSP....}

Figure 7. Co-purification of enolase with the nativeCTD and characterization of the binding segment. A, SDS-PAGE (left) showing that enolase and native CTD are both present in a peak eluted from an S200 column. The native gel (right) shows that the native-CTDenolase complex, eluted as a single peak from the S200 column, runs as a single band. The identities of the components were corroborated by amino-terminal sequencing. B, Limited protease digestion of the native-CTDenolase complex with chymotrypsin, analysed by nondenaturing gel electrophoresis. Lanes $0,1,2$ and 3 correspond to number of hours after chymotrypsin addition. The predominant digest species was shown to contain both enolase and a fragment of the CTD by amino-terminal sequencing, shown in $\mathrm{C}$.
(Figure 7A). Based on its elution volume from the S200 column, the apparent molecular mass of the complex was $10^{3} \mathrm{kDa}$, which is nearly three times the expected size for an enolase dimer with two CTD proteins bound. The apparently large mass of the complex is most likely due to the anomalous volume of the predominantly unstructured CTD.

The activity of the enolase within the nativeCTD-enolase complex was measured as 128 i.u. $\mathrm{mg}^{-1} \quad\left(1\right.$ i.u. $\left.=1 \mu \mathrm{mol} \mathrm{min}{ }^{-1}\right)$. Correcting for the composition of the complex, this activity is in the same range as the values of $260 \mathrm{i} . \mathrm{u} . \mathrm{mg}^{-1}$ and 147 i.u. $\mathrm{mg}^{-1}$ cited for the activity of enolase alone ${ }^{41,42}$ and the value of 173 i.u. $\mathrm{mg}^{-1}$ for enolase activity within degradosome preparations. ${ }^{22}$ It thus appears that the activity of enolase is not significantly affected by binding to the CTD.

The native-CTD-enolase complex is very sensitive to partial proteolysis by protease K. It is less sensitive to partial digestion by chymotrypsin (Figure 7B), and this enabled identification of the minimal binding fragment of native-CTD to enolase by native PAGE and N-terminal sequencing analysis. The fragment bound to enolase was found to start at residue 816 of RNase E (Figure 7C), and from its molecular mass was presumed to extend roughly to residue 1038 . No other species was observed by $\mathrm{N}$-terminal sequencing analysis, so identifying the minimal digest complex to be a single species. The minimal enolase-binding fragment therefore incorporates segment $C$, predicted to be a RISP by the PONDR ${ }^{\circledR}$ analysis (Figure $4 \mathrm{~A}$ ).

A synthetic 18 amino acid residue peptide encompassing segment C (RNase E residues 833850) was tested for binding to enolase. Nanoflow mass spectrometry analysis of enolase alone gave a spectrum showing a charge state series that represents one species with an observed mass of $91,060( \pm 8) \mathrm{Da}$, corresponding to the dimeric form of the protein (theorectical mass of 91,047 Da) (Figure 8A, black trace). Upon addition of peptide $\mathrm{C}$ to enolase in an $\sim 1.5$ stoichiometric excess, two charge state series were identified (Figure 8A, red trace). Series $B$ with a molecular mass of $93,158( \pm 14) \mathrm{Da}$, corresponding to an enolase dimer with one peptide $C$ bound, was the predominant species observed (theoretical mass of $93,089 \mathrm{Da})$. In addition we observe a charge state series C with a mass of $95,195( \pm 12) \mathrm{Da}$, corresponding to one enolase dimer bound to two peptide C molecules (theoretical mass 95,131 Da). MS/MS analysis of the B +19 complex ion confirmed the composition of the species to be that of an enolase dimer bound to peptide C (Figure 8B).

We tested for the binding of helicase RhlB to the purified native-CTD-enolase complex by sizeexclusion chromatography and native PAGE analysis under various conditions, but no larger complex was observed. Also, no increase in helicase RhlB activity could be observed upon addition of helicase RhlB to the native-CTD-enolase complex, even though the R-domain region, shown previously to bind and cause an increase in the 


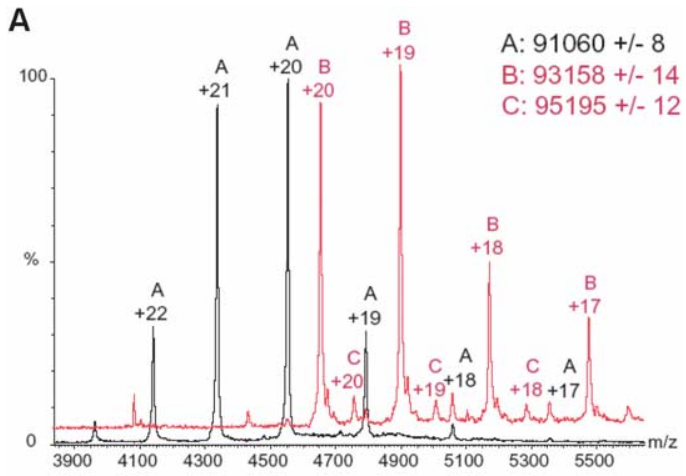

B

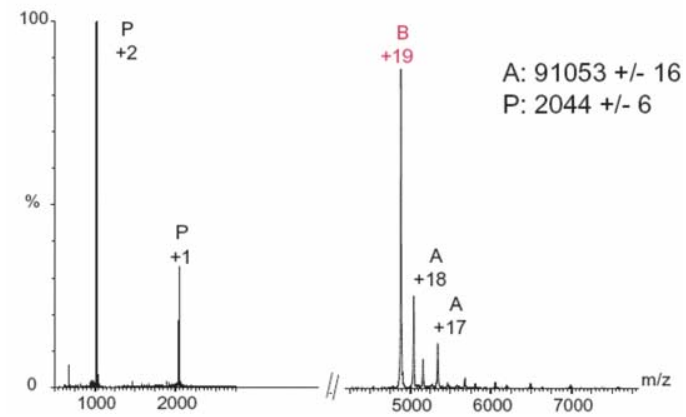

Figure 8. Nanoflow-ESI mass spectra of enolase and peptide $\mathrm{C}$ recorded under non-dissociating conditions. A, ESI mass spectrum of enolase alone (black trace) and a mixture of enolase and peptide C (red trace), vertically offset from 0 for clarity. Charge state series A corresponds to enolase dimer; series B corresponds to enolase dimer with one peptide $C$ bound and series $C$ corresponds to enolase dimer with two peptide $C$ bound B, MS/MS analysis of enolase-peptide C complex B +19 ion. Series A corresponds to enolase dimer and series $\mathrm{P}$ corresponds to peptide $\mathrm{C}$.

ATPase activity of helicase RhlB under the same conditions, was present within the native-CTD protein. This further indicated the lack of helicase RhlB binding to the native-CTD-enolase complex.

\section{Binding of PNPase to RNase E CTD}

We similarly tested for the binding of PNPase to the purified native-CTD-enolase complex by sizeexclusion chromatography and native PAGE analysis under various conditions, but likewise no larger complex was observed. The C-terminal region of RNase E (residues 1038-1061) is absent from the native-CTD-enolase complex. This region is part of segment $D$ that was identified by the PONDR $^{\circledR}$ analysis as being an RISP (residues 1021-1061; Figure 4). The binding of a synthetic 40 amino acid residue peptide encompassing segment D (RNase E residues 1021-1061) was tested for binding to PNPase. Nanoflow mass spectrometry analysis was again used to define complexes formed (Figure 9). Analysis of PNPase alone gave a spectrum showing a charge state series that represents essentially one species with an observed mass of $236,080( \pm 8) \mathrm{Da}$, correspond-

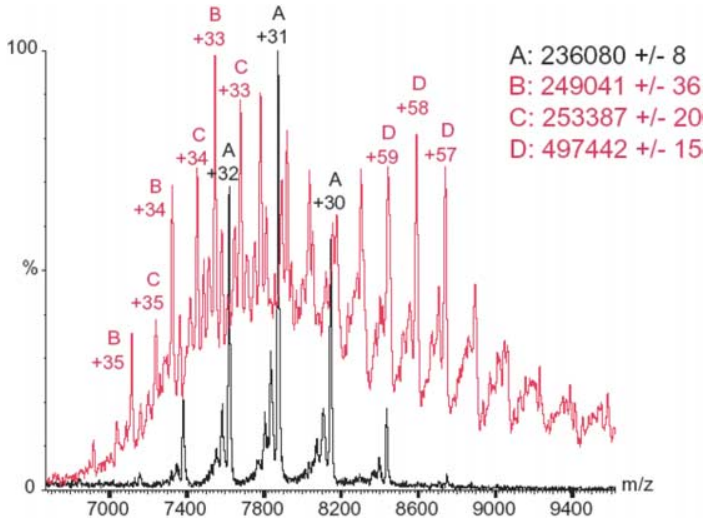

Figure 9. Nanoflow-ESI mass spectra of PNPase and peptide $\mathrm{D}$ recorded under non-dissociating conditions. A, ESI mass spectrum of PNPase alone (black trace) and a mixture of PNPase and peptide D (red trace), vertically offset from 0 for clarity. Charge state series A corresponds to PNPase trimer. A small population of truncated PNPase trimers are also observed, most likely resulting from loss of the His-tag from the protein. Series D corresponds to a dimer of PNPase trimers with six peptide D molecules bound. Dissociation products of series D gives series B and C, corresponding to PNPase trimer with three and four peptide D molecules bound, respectively. Dissociation products are observed as a consequence of the use of an acceleration strategy necessary for obtaining narrower peak widths for improved resolution. ${ }^{44}$

ing to the trimeric form of the protein (theoretical mass of 235,477 Da) (Figure 9, black trace). The trimeric state observed by mass spectrometry agrees with the crystal structure of S. antibioticus PNPase, which shows extensive subunit interfaces and suggests that the trimer is stable. ${ }^{43}$ Minor peaks preceding each charge state of the predominant series represent minor truncations of the protein, most likely corresponding to the loss of the Histag. Addition of Peptide D to PNPase in stoichiometric excess gave evidence for a charge series corresponding to a species with a molecular mass of 497,442( \pm 15$) \mathrm{Da}$, (Figure 9, red trace, series D). This is consistent with a dimer of PNPase trimers with six peptide D molecules bound, which equates to one peptide D per PNPase monomer (theoretical mass of 496,950 Da). Also, we observed a trimer of PNPase with three and four peptide D molecules bound (Figure 9, series B and C respectively). Both series B and C are most likely collision-induced dissociation products of the dimer of trimers with six peptide D molecules bound. This is evidenced by the higher average charge state for series B and C compared to those observed for the PNPase trimer series. Such dissociation products are observed as a consequence of using acceleration to obtain narrower peak widths for improved resolution. ${ }^{44}$ In light of these results showing that peptide $\mathrm{D}$ can bind to PNPase, it seems likely that PNPase cannot bind to the native-CTD-enolase complex described 
previously because that complex is lacking the D segment.

\section{Discussion}

We have developed purification protocols for RNase E CTD and two of its shortened versions (referred to here as R-domain and native CTD). All three proteins have been shown to be functionally active using assays of RNA-binding and protein-to-protein interaction, as summarised in Figure 10. Programs that identify disordered/ unstructured proteins (GlobPlot and PONDR ${ }^{\circledR}$ ) suggest that the CTD is largely lacking in defined conformation. Supporting this prediction, our observations from solution X-ray scattering, circular dichroism and limited protease digestion indicate that the CTD has little structural character. However, within the CTD there are three short segments of 10-40 residues that are predicted to be RISPs, and a larger region of roughly 80 residues that is proposed to be a coiled coil. The segments of predicted structural propensity are summarized in the top of Figure 10 and are labelled A, B, C and D.

We have found that the CTD can be cross-linked to itself, which is consistent with the findings reported by Vanzo et al., ${ }^{19}$ that RNase E can selfinteract. Using the yeast two-hybrid approach, the self-interaction domain has been mapped to the N-terminal end of the CTD (residues 500-752). This section encompasses the RISP segment A, corresponding to residues 565-585 (Figures 4 and 10), and we propose that this region may be involved in self-association.

Also included in the self-interaction domain is the site labelled $\mathrm{B}$, corresponding to residues 633712. This segment is predicted to form a coiled coil (Figures 4 and 10), which could conceivably contribute to an oligomerization interface. The coiled-coil region also contains an arginine-rich RNA-binding domain (RBD; residues 604-688) which has been shown to recruit RNase E to structured RNAs. ${ }^{45,46}$ The R-domain includes the putative coiled-coil region, and we have shown here that the domain binds avidly to $7 \mathrm{~S}$ rRNA by band-shift analysis (Figure 5C). The affinity of the
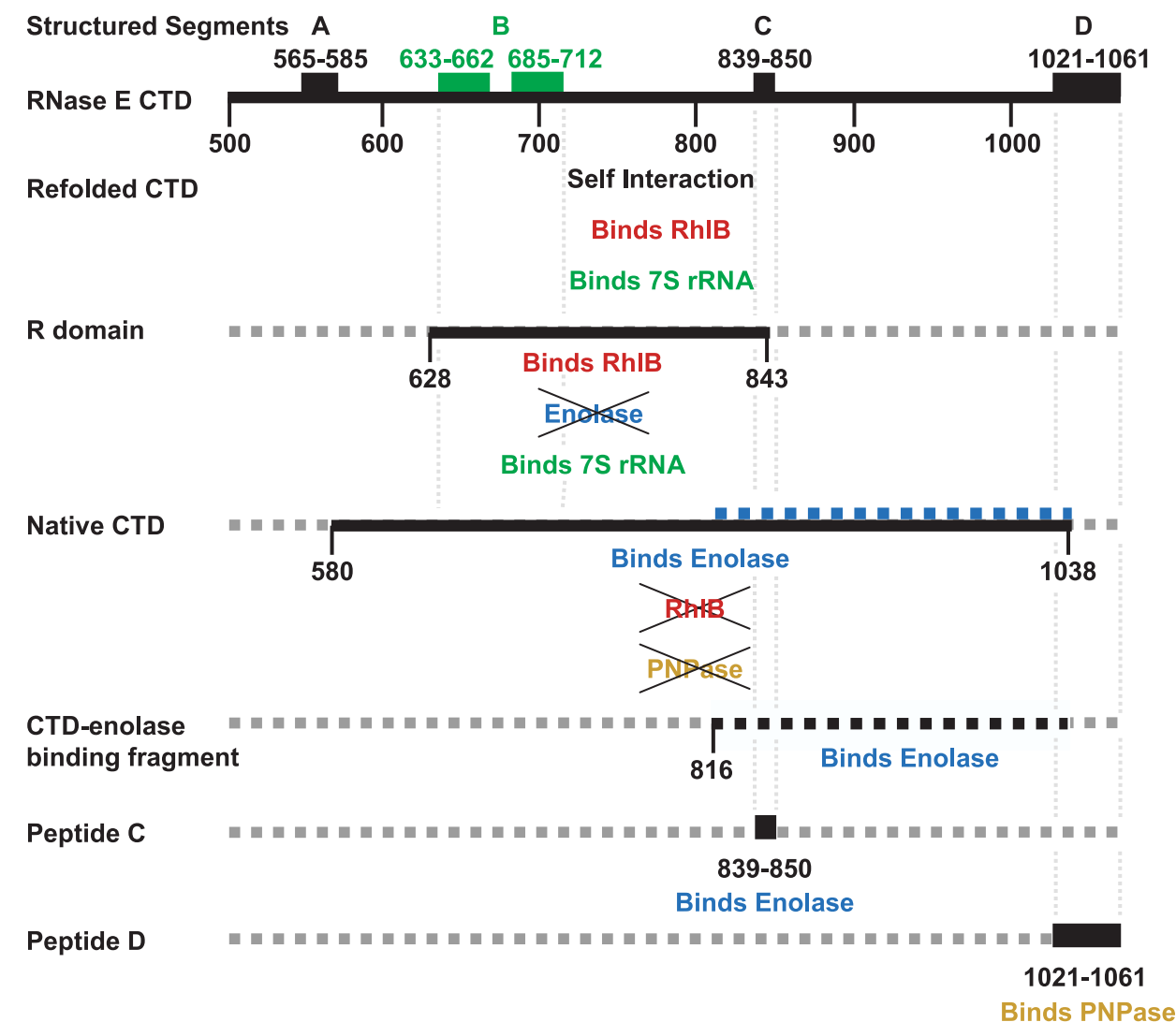

Figure 10. A summary of the putative CTD structured domains and interaction sites. RNase E CTD (residues 5001061 ) is shown with RISPs labelled A to D. The RISPs that are based on PONDR ${ }^{\circledR}$ analysis are boxed in black and labelled A, C and D. The region of predicted coiled-coil structure based on COILS analysis is boxed in green and labelled B. The refolded CTD can self-associate and bind to helicase RhlB and 7S rRNA. The R-domain and native CTD are aligned with the RNase E CTD. The finding that the R-domain interacts avidly with the helicase RhlB, but cannot bind enolase under the same conditions is noted, as is its binding to $7 \mathrm{~S}$ rRNA. The native CTD co-purifies with enolase and the minimal enolase-binding domain, identified here by limited proteolysis, is shown by the broken blue line. The native CTD enolase complex was not observed to bind PNPase or helicase RhlB. The binding of a peptide encompassing segment $C$ to enolase and segment D to PNPase are also noted. 
R-domain for the $7 \mathrm{~S}$ rRNA is comparable to that of the CTD (Figure 3B). Therefore, it is likely that the coiled-coil region identified here is involved in binding to structured RNAs. This region might function analogously to the coiled-coil region in the conserved N-terminal domain of seryl-tRNA synthetase, which contacts the tRNA. ${ }^{47}$ Circular dichroism spectroscopy suggests that the isolated CTD and R-domain lack helical character, which might at first seem inconsistent with the prediction of a coiled-coil character. However, the N-terminal domain of the seryl-tRNA synthetase also shows disorder in the absence of its tRNA substrate. Thus, in analogy with the synthetase, the coiledcoil region of RNase E CTD might be induced to fold by RNA binding.

The second arginine-rich region within the CTD, identified by Leroy et l. $^{46}$ as being involved in RNA binding (residues 796-819), was not identified as having structure from this study. It is possible that this region also gains structure upon RNA binding.

We observe that the R-domain binds helicase avidly in a $1: 1$ stoichiometric ratio, and we found by circular dichroism that this interaction does not induce significant folding of the R-domain. We also show that the R-domain stimulates the ATPase activity of the helicase, in agreement with the findings reported by Vanzo et al. ${ }^{19}$ The R-domain contains an incomplete C segment (residues 839-850; Figures 4 and 10), so it seems unlikely that this RISP is the binding site of helicase. Also, the Rdomain contains the RISP segment $B$, but we have recently found that this segment (residues 633712) does not interact with helicase RhlB (Ola Zaid \& B.F.L., unpublished results). This is in accord with the findings reported by Liou et al., ${ }^{48}$ who observed that RNase E residues 684-784 are sufficient for binding helicase RhlB, and Vanzo et al., ${ }^{19}$ who found that helicase would not bind to RNase E lacking residues 728-845. Taken together, these earlier findings suggest that residues within the 728-784 region must be important for the interaction. This region is predicted to be lacking in defined structure. It therefore seems likely that helicase RhlB binds to an unstructured region of CTD, and that binding does not induce significant folding of the CTD.

The entire $C$ segment (residues 839-850; Figures 4 and 10) is found within the native-CTD fragment that was co-purified with enolase. Indeed, we identified a minimal enolase-binding site, by partial proteolysis of the native-CTD-enolase complex, which encompasses the site $C$, suggesting it to be the enolase-binding site. Also, we note that enolase does not bind to the R-domain which contains an incomplete $C$ segment. Using nanoflow electrospray mass spectrometry we have shown that a synthetic peptide corresponding to segment $C$ makes an avid, stoichiometric complex with enolase (Figure 8). The complex of enolase-peptide C has recently been crystallized and efforts are focussing on identifying the binding site of peptide
C on enolase (Vidya Chandran \& B.F.L., unpublished results).

Under the conditions examined here, we did not observe binding of helicase RhlB to the nativeCTD-enolase complex. It is possible that the bound enolase might restrict the access of the helicase to its CTD-binding site. Enolase and helicase co-purify in degradosome preparations, but it is possible that they are in fact located on separate RNase E CTDs in an oligomeric organization. We have identified the NTD of RNase E as being tetrameric ${ }^{27}$ and our results, together with the findings reported by Vanzo et al., ${ }^{19}$ have shown that the CTD can dimerize. To date, there is no biochemical evidence for enolase and helicase RhlB binding to the same single RNase E CTD, so perhaps this is possible only under certain conditions, for example, in the presence of specific RNAs or complete degradosome complex formation. If the enzymes in fact compete for binding sites, this could act as a mechanism to link cellular levels of enolase with degradosome activity.

The fourth RISP site identified, D (residues 1022-1061; Figures 4 and 10), has been shown to bind PNPase by non-dissociating mass spectrometry (Figure 9), and pull-down assay analysis (Jenny Long \& B.F.L., unpublished results). This is in agreement with Vanzo et al. ${ }^{19}$ who mapped PNPase association to segment 844-1045. The finding that PNPase could not be associated with the native-CTD-enolase complex is in agreement with this proposal, as the native-CTD appears to be lacking residues $\mathrm{C}$-terminal to amino acid residue $\sim 1038$, and therefore is missing part of the PNPase-binding site.

In contrast to the structurally indeterminate CTD, the NTD has a globular character. ${ }^{27}$ As the NTD forms a tetramer while the CTD forms dimers, it seems likely that the full-length RNase $\mathrm{E}$ may be organized as a dimer-pair. We imagine that the NTD forms a tetrameric core of the degradosome and that the flexible CTD recruits the other enzymes around this centre. This organization may be necessary for the efficient binding of the other degradosome components and substrate RNA.

Although best characterized in E. coli, other bacterial species may have mRNA-degrading complexes that are homologous or analogous with the RNA degradosome. ${ }^{49}$ For example, the Rhodobacter capsulatus RNase E assembles a complex that is similar to the E. coli RNA degradosome, but may lack the PNPase. ${ }^{50}$ Also, the Streptomyces coelicolor RNase E orthologue has conserved catalytic and PNPase-binding regions, but the domain organisation is shuffled compared to the E. coli enzyme, so that the catalytic domain resides towards the middle of the protein and both termini are capable of interacting with PNPase. ${ }^{51}$ It seems that evolution may have found different ways of creating a degradosome assembly mediated by the CTD or CTD-like domain. ${ }^{17,52}$

The NTD is highly conserved amongst the 
bacteria and certain plants. In E. coli this domain is essential for cell viability ${ }^{53}$ while in contrast the CTD is not. But, lack of CTD does slow growth appreciably and affects the transcript composition, ${ }^{54}$ so it seems likely that it confers selective advantages to E. coli and perhaps to closely related bacteria. The CTD portion is highly divergent amongst the members of the RNase E family, but this is perhaps not surprising given that it appears to be an intrinsically unstructured protein. It seems that the domain may have diverged rapidly among the bacteria, but the punctuated RISPs identified here are much more strongly conserved..$^{55}$ It is possible that the CTD domain may be a comparatively recent adaptation in the evolution of the RNase E of the $\gamma$-proteobacteria lineage, and it may be a specialization for fine-tuning the balance of transcript populations within the cell through the assembly of the degradosome.

\section{Materials and Methods}

\section{His-tagged RNase E CTD expression and purification under denaturing conditions}

The CTD of the rne gene was cloned into a pET15b vector (Novagen). The construct encodes for an N-terminal hexa-histidine tag, followed by a thrombin cleavage site and rne sequence corresponding to the RNase E residues 1-26 followed by 498-1061 (Figure 1B). E. coli strain BL21(DE3) was transformed with the vector for over-expression. Cultures were grown at $37^{\circ} \mathrm{C}$ and induced at an absorbance at $600 \mathrm{~nm}$ of $0.5-0.6$ with $1 \mathrm{mM}$ isopropyl $\beta$-D-1-thiogalactopyranoside (IPTG). Cells were harvested three hours after induction by centrifugation at $4000 \mathrm{~g}$ for 20 minutes at $4{ }^{\circ} \mathrm{C}$, washed once with ice-cold phosphate-buffered saline (PBS) supplemented with Complete Block (Roche) protease inhibitors, pelleted again by centrifugation and stored frozen at $-20{ }^{\circ} \mathrm{C}$.

Cell pellets were resuspended in ice-cold PBS supplemented with $6.5 \mathrm{M}$ urea (PBS-U) and Complete Block protease inhibitors (Roche), placed in an ice-bath and sonicated for a total of one minute using a low-intensity probe (Misonix). The cellular lysate was clarified by centrifugation at $30,000 \mathrm{~g}$ for 25 minutes at $4{ }^{\circ} \mathrm{C}$. The cleared lysate was collected and passed through a $0.2 \mu \mathrm{m}$ filter and loaded onto a His Trap column (Amersham) equilibrated with PBS-U at $4{ }^{\circ} \mathrm{C}$. The cleared lysate was circulated slowly through the column for 30 minutes. The column was washed with PBS-U containing $20 \mathrm{mM}$ imidazole, and the sample was eluted with PBS-U containing $500 \mathrm{mM}$ imidazole. The washing and elution buffers were supplemented with $500 \mathrm{mM} \mathrm{NaCl}$, Complete Block (Roche) protease inhibitors and $50 \mathrm{mM}$ glycine to scavenge cynate. The eluted CTD was pooled and concentrated in a $30 \mathrm{kDa}$ centrifugal concentrator (Vivascience) at $6000 \mathrm{~g}$, and subsequently buffer-exchanged into PBS-U using PD-10 columns (Amersham). The protein was then applied to a HiTrap Q column (Amersham) equilibrated with buffer A (20 mM Tris- $\mathrm{HCl}$ (pH 7.6), 6.5 M urea with Complete Block) and eluted with a gradient of $0-100 \%$ buffer B (buffer $\mathrm{A}+1 \mathrm{M} \mathrm{NaCl}$ ). Fractions containing the CTD were pooled, concentrated to $5 \mathrm{mg}$ / $\mathrm{ml}$ and frozen at $-20{ }^{\circ} \mathrm{C}$.

\section{RNase E CTD refolding}

An aliquot $(100 \mu \mathrm{l})$ containing $0.5 \mathrm{mg}$ of RNase E CTD in PBS-U (as described above), was flash diluted 20-fold into $20 \mathrm{mM}$ sodium potassium phosphate buffer $(\mathrm{pH}$ 7.7) supplemented with $250 \mathrm{mM} \mathrm{Na} \mathrm{SO}_{4}$. The protein was further dialyzed against a reservoir of the phosphate buffer on ice and finally concentrated to approximately $0.2 \mathrm{mg} / \mathrm{ml}$ in a $30 \mathrm{kDa}$ centrifugal concentrator (Vivascience). The final concentration was confirmed by amino acid composition analysis (Protein and Nucleic Acid Chemistry Facility, University of Cambridge).

\section{The 7 S rRNA electrophoretic mobility-shift assay}

His-tagged R-domain, corresponding to residues 628 843 (see Figure 1B), was purified under denaturing conditions as described above for the His-tagged CTD. Denatured CTD and R-domain proteins eluted from the His Trap column were diluted 20-fold into $50 \mathrm{mM}$ Tris$\mathrm{HCl}$ ( $\mathrm{pH} 8.0), 300 \mathrm{mM} \mathrm{NaCl}, 10 \%$ (v/v) glycerol, $0.1 \mathrm{mg} / \mathrm{ml}$ of acetylated BSA, $1 \mathrm{mM}$ EDTA, $1 \mathrm{mM}$ DTT, $1 \mathrm{mM}$ PMSF, $2 \mu \mathrm{g} / \mathrm{ml}$ of aprotinin, $0.8 \mu \mathrm{g} / \mathrm{ml}$ of pepstatin $\mathrm{A}, 0.8 \mu \mathrm{g} / \mathrm{ml}$ of leupeptin and incubated at $30^{\circ} \mathrm{C}$ for five minutes before quenching on ice. The solutions were clarified by centrifugation at $14,400 \mathrm{rpm}$ in an Eppendorf centrifuge at $4{ }^{\circ} \mathrm{C}$ for 20 minutes. Triton $\mathrm{X}$ 100 was added to a final concentration of $0.2 \%(\mathrm{v} / \mathrm{v})$ and the renatured proteins were stored at $-20^{\circ} \mathrm{C}$.

Refolded protein (8 $\mathrm{nM} \mathrm{CTD} \mathrm{or} \mathrm{R-domain)} \mathrm{was} \mathrm{incu-}$ bated for 30 minutes at $30{ }^{\circ} \mathrm{C}$ with ${ }^{32} \mathrm{P}$-labelled $7 \mathrm{~S}$ rRNA $(4 \mathrm{nM})$ and competitor yeast RNA $(0.78-50 \mu \mathrm{g} / \mathrm{ml})$ in binding buffer ( $50 \mathrm{mM} \mathrm{NaCl}, 10 \mathrm{mM}$ Tris- $\mathrm{HCl}(\mathrm{pH} 7.5)$, $10 \%$ glycerol, $0.1 \%$ (w/v) Genapol X-080, 1 mM EDTA, $1 \mathrm{mM}$ DTT, 40 i.u. of RNasin) and then quenched on ice. The reactions were analyzed by $0.5 \times$ TBE native-PAGE $(5 \%, 29: 1(\mathrm{w} / \mathrm{w})$ acrylamide:bis-acrylamide) containing $0.1 \%(\mathrm{v} / \mathrm{v})$ Triton $\mathrm{X}-100$ at $4{ }^{\circ} \mathrm{C}$. After drying, the gels were analyzed by phosphorimaging. The $7 \mathrm{~S}$ rRNA, which is a fragment of the $9 \mathrm{~S}$ precursor of $5 \mathrm{~S}$ rRNA, was synthesized by transcription with bacteriophage T7 RNA polymerase. Authentic $7 \mathrm{~S}$ rRNA has a monophosphorylated adenine residue at its $5^{\prime}$ end, ${ }^{45}$ whereas the transcript used in these experiments has an additional guanosine base that is triphosphorylated (i.e. $5^{\prime}$ pppGpA).

\section{Expression of RNase E native-CTD and purification of the native-CTD-enolase complex}

A version of the CTD without a histidine tag (Figure 1B) was cloned in vector pET11a and over-expressed in strain BL21 (DE3). This protein was purified under native conditions, as a complex with enolase, and is referred to here as native-CTD.

Thawed cell pellets were resuspended in lysis buffer (50 mM Tris- $\mathrm{HCl}$ (pH 7.5), 5\% glycerol and protease inhibitors), fractured by sonication and centrifuged at $35,000 \mathrm{~g}$ for 30 minutes. Semi-purified enolase (see method below) was mixed with the soluble extract and incubated at room temperature for 30 minutes. The mixture was then applied to a HiTrap Q ion-exchange column (Amersham Pharmacia Biotech) equilibrated with lysis buffer and the complex eluted using a $0-600 \mathrm{mM}$ $\mathrm{NaCl}$ gradient over 20 column volumes. The nativeCTD-enolase complex eluted at $240-280 \mathrm{mM} \mathrm{NaCl}$. Fractions were pooled, concentrated and applied to a Superdex 200 gel-filtration column (HR10/30; Amersham 
Pharmacia Biotech) equilibrated with $50 \mathrm{mM}$ Tris $-\mathrm{HCl}$ (pH 7.5), $0.3 \mathrm{M} \mathrm{NaCl}, 10 \%$ glycerol, and protease inhibitors. The complex eluted after $\sim 9-11 \mathrm{ml}$, corresponding to an apparent molecular mass of roughly $10^{3} \mathrm{kDa}$.

\section{Expression and purification of enolase}

The expression and purification of E. coli enolase was as described by Kühnel \& Luisi. ${ }^{42}$ For semi-purified enolase, after the final ammonium sulphate-precipiation step, the enolase was buffer-exchanged into $50 \mathrm{mM}$ Tris $-\mathrm{HCl}(\mathrm{pH} 7.5), 5 \%$ glycerol and protease inhibitors (this material was used in co-purification with the native CTD).

\section{Enolase activity assay}

The activity of enolase was assayed as described by Kühnel \& Luisi. ${ }^{42}$ Five micrograms of native-CTD-enolase complex was assayed, which equates to $2 \mu \mathrm{g}$ of enolase based on a 1:1 stoichiometric complex and normalized to molecular mass.

\section{Expression and purification of helicase RhIB}

Expression of RhlB was as described by Py et al.22 After three hours post-induction, the cells were harvested and resuspended in lysis buffer $(0.4 \mathrm{M} \mathrm{NaCl}$, $20 \mathrm{mM}$ Tris $-\mathrm{HCl}\left(\mathrm{pH}\right.$ 8.0)) and stored at $-80^{\circ} \mathrm{C}$. Thawed cells were resuspended in lysis buffer with protease inhibitor (Roche). Cells were broken with a French press and the lysate was clarified by centrifugation at $20,000 \mathrm{~g}$ for 20 minutes at $4{ }^{\circ} \mathrm{C}$. RhlB was precipitated from the supernatant by adding $\mathrm{NH}_{4} \mathrm{SO}_{4}$ to $60 \%$ saturation. The sample was stirred at $4{ }^{\circ} \mathrm{C}$ for one hour and the pellet collected by centrifugation at $30,000 \mathrm{~g}$ for 40 minutes. RhlB was resuspended in $300 \mathrm{mM} \mathrm{NaCl}, 2 \mathrm{mM}$ DTT, 20 mM Mes (pH 6.5) and loaded onto a heparin column (Amersham Biosciences). RhlB eluted with a linear gradient from $0 \%$ to $75 \%$ of the resuspension buffer supplemented with $2 \mathrm{M} \mathrm{NaCl}$. The final step involved use of a HiLoad 16/10 Phenyl Sepharose column (Pharmacia Biotech) with a reverse salt gradient at room temperature. The buffers used were $20 \mathrm{mM}$ sodium phosphate and $5 \mathrm{mM}$ DTT at $\mathrm{pH} \mathrm{7.2,} \mathrm{and} \mathrm{the} \mathrm{binding} \mathrm{(high} \mathrm{salt)} \mathrm{buf-}$ fer was further supplemented with $1.2 \mathrm{M}$ ammonium sulphate. The RhlB-containing fractions were pooled and concentrated (Vivaspin $20 \mathrm{kDa}, 30 \mathrm{kDa}$ cut-off). The identity of the protein was verified by amino-terminal sequencing and electrospray mass spectrometry.

\section{Helicase RhIB activity assay}

The ATPase activity of the helicase RhlB in the presence of native-CTD-enolase complex was assayed by the method of Vanzo et al. ${ }^{19}$

\section{Expression and purification of R-domain and the helicase-R-domain complex}

R-domain (Figure 1B) was expressed as described in Vanzo et al.,19 where it is referred to as RneHC2. Cells were grown in $2 \times$ YT medium with $100 \mu \mathrm{g} / \mathrm{ml}$ of ampicillin and induced at an absorbance at $600 \mathrm{~nm}$ of $0.5-0.6$ with $1.0 \mathrm{mM}$ IPTG. For native purification the cells were harvested after three hours in $50 \mathrm{mM}$ Tris $-\mathrm{HCl}(\mathrm{pH}$ $8.0), 1 \mathrm{mg} / \mathrm{ml}$ of lysozyme, $2 \mathrm{mM}$ DTT, $2 \mathrm{mM}$ EDTA,
$0.1 \%(\mathrm{w} / \mathrm{v})$ Tween-20 and treated with DNase I. The cells were ruptured with a French press. The lysate was spun and the supernatant was applied to a HiTrap heparin column equilibrated with $50 \mathrm{mM}$ Mes ( $\mathrm{pH}$ 6.5), $2 \mathrm{mM}$ DTT, 5\% glycerol. The protein was eluted with a linear salt gradient in the above buffer supplemented with $2 \mathrm{M} \mathrm{NaCl}$. The enriched fractions were pooled, dialyzed and then applied to a heparin affinity matrix. The identity of the protein was confirmed by N-terminal sequencing and electrospray mass spectrometry.

Purified R-domain was mixed with purified RhlB helicase in a $1.5: 1$ stoichiometric ratio, incubated for $30 \mathrm{~min}-$ utes and then applied to a Superdex S200 HR10/30 sizeexclusion column equilibrated with $100 \mathrm{mM} \mathrm{NaCl}$, $10 \mathrm{mM} \mathrm{MgCl}$, $5 \mathrm{mM}$ Tris-HCl ( $\mathrm{pH}$ 8.0). The RhlB and $\mathrm{R}$-domain co-eluted. In tests of the recruitment, enolase, R-domain and RhlB were mixed in a $1: 1.5: 1$ ratio.

As described earlier, a histidine-tagged version of the $\mathrm{R}$-domain was purified and refolded in the same manner as the CTD. This material was used for binding experiments with $7 \mathrm{~S}$ rRNA.

\section{Limited proteolysis of the RNase E CTD, helicase RhIB and the native CTD-enolase complex}

Proteolytic reactions were initiated by the addition of $0.1 \mu \mathrm{g}$ of sequencing grade chymotrypsin (Roche), corresponding to $1 / 1000$ of the target protein mass. Samples were collected at intervals and either mixed $1: 1$ with native PAGE loading buffer and stored at $-20{ }^{\circ} \mathrm{C}$ until native-PAGE analysis or the reactions were quenched by addition of $1: 1$ of SDS-PAGE loading buffer, followed by incubation at $95{ }^{\circ} \mathrm{C}$ for three minutes and then SDS-PAGE analysis. Limited digest products were analysed by $\mathrm{N}$-terminal sequencing after blotting onto PVDV membranes.

\section{Chemical cross-linking}

Interactions between the refolded RNase E CTD and the degradosome component helicase RhlB were tested by reactions with the cross-linking agent dimethyl suberimidate (DMS). The refolded CTD $(0.3 \mathrm{mg} / \mathrm{ml})$ was incubated with helicase in an approximate $1: 1$ ratio. As controls the individual proteins were assayed in isolation. Prior to reaction, the samples were bufferexchanged into $0.2 \mathrm{M}$ triethanolamine ( $\mathrm{pH} 8.0)$ and concentrated to $\sim 1 \mathrm{mg} / \mathrm{ml}$. DMS was added to a final concentration of $10 \mathrm{mM}$. Samples of the isolated proteins, pre-cross-linking and timed intervals after addition of DMS were collected and analysed by SDS-PAGE. Protein identity was corroborated by in-gel digestion with trypsin and MALDI-TOF mass spectrometry by Dr Len Packman at the Protein and Nucleic Acid Chemistry Facility, University of Cambridge.

\section{Expression and purification of PNPase}

Details of the cloning of the construct for PNPase expression are given by Vanzo et al. ${ }^{19}$ Cells were grown in $2 \times \mathrm{YT}$ medium with $100 \mu \mathrm{g} / \mathrm{ml}$ of ampicillin and induced at an absorbance at $600 \mathrm{~nm}$ of $0.5-0.6$ with $0.1 \mathrm{mM}$ IPTG. Over-expression was found to be optimal when the temperature was reduced to $25^{\circ} \mathrm{C}$ at the time of induction. The cell lysates were clarified by centrifugation and ammonium sulphate was added to the supernatant to $40 \%$ saturation. The sample was spun at $30,000 \mathrm{~g}$ for 30 minutes at $4{ }^{\circ} \mathrm{C}$, and this supernatant was 
then adjusted to $70 \%$ saturation with ammonium sulphate, at which point PNPase precipitates. The precipitated PNPase was resuspended in $2 \mathrm{ml}$ of low-salt buffer (50 mM Tris- $\mathrm{HCl}(\mathrm{pH}), 50 \mathrm{mM} \mathrm{NaCl}, 10 \%$ glycerol) and exchanged into the same buffer by using PD10 columns (Amersham). The final step in the purification was application to a HiTrapQ column at room temperature and elution with a linear gradient from $50 \mathrm{mM}$ to $2 \mathrm{M} \mathrm{NaCl}$ in the same buffer. At this stage the protein is greater than $95 \%$ pure, as judged from SDSPAGE.

\section{Solution X-ray scattering}

Data were collected at Daresbury Laboratory (Station 2.1) at 4.25 and $1 \mathrm{~m}$ sample-to-detector distance using a 2D multiwire proportional counter. The sample of RNase E CTD used was at $1 \mathrm{mg} / \mathrm{ml}$. The Guinier approximation was used to estimate the radius of gyration $\left(R_{\mathrm{g}}\right)$ from the slope of a plot of scattering intensity, $I(q)$ as a function of $q^{2}$, where $q=4 \pi \sin \theta / \lambda, 2 \theta$ is the scattering angle and $\lambda$ is the wavelength. For this analysis, only the data at very low $q$-values were used $\left(0.008 \AA^{-1}<q<0.017 \AA^{-1}\right)$. These and other parameters were also evaluated by analysis of the whole scattering profile using the program GNOM. ${ }^{56}$ Also, the maximum particle dimension $\left(D_{\operatorname{MAX}}\right)$ was calculated. The sample of the NTD was purified and analysed as described by Callaghan et al. $^{27}$

\section{Circular dichroism}

The refolded CTD was analysed by circular dichroism (CD; Aviv Instruments Inc., model 215) in $1.0 \mathrm{~mm}$ cuvettes (Starna, Optiglass Ltd). The spectra were collected between $185 \mathrm{~nm}$ and $260 \mathrm{~nm}$, with $1 \mathrm{~nm}$ steps at $2{ }^{\circ} \mathrm{C}$, $22{ }^{\circ} \mathrm{C}, 42{ }^{\circ} \mathrm{C}, 62{ }^{\circ} \mathrm{C}$ and $82{ }^{\circ} \mathrm{C}$ with a time constant of $100 \mathrm{~ms}$. Three independent runs were recorded, mean values calculated and the buffer signal subtracted. The CD data were normalized with the $M_{\mathrm{W}}(67,666 \mathrm{Da})$, number of amino acid residues (610) and the concentration of the protein to obtain mean molar residue ellipticity values $\left([\theta]\right.$, deg $\left.\mathrm{cm}^{2} / \mathrm{dmol}\right)$.

Far-ultraviolet circular dichroism spectra were collected from the RhlB helicase, the R-domain, and the Rdomain-helicase complex at station 3.1 at the Daresbury Synchrotron Radiation Source. Data were collected from $170 \mathrm{~nm}$ to $260 \mathrm{~nm}$. The proteins were in $50 \mathrm{mM}$ sodium potassium phosphate buffer ( $\mathrm{pH} 7.5$ ). The spectra were background-corrected, scaled according to protein concentration and processed to estimate the secondary structure components.

\section{Sequence analysis of the RNase E}

The E. coli RNase E protein sequence was analysed using the Predictor of Protein Disorder and Globularity $\left(\text { GlobPlot }^{\text {ru }} 1.2,\right)^{32} \dagger$ using the REMARK-456 disorder propensity and default settings. Also used was the Predictors of Natural Disordered Regions (PONDR ${ }^{\circledR}, 33-37+$ with default settings. Coiled-coil domains were analysed using the COILS program. ${ }^{38}$

$\dagger$ http://globplot.embl.de/

$\ddagger$ http://www.pondr.com

\section{Nanoflow-ES mass spectrometry}

Samples for analysis were buffer exchanged into $1 \mathrm{M}$ ammonium acetate using BioRad micro-Spin columns. Mass spectra of the proteins at a concentration of $\sim 20$ $30 \mu \mathrm{M}$ were collected on a modified Q-ToF2 mass spectrometer ${ }^{57}$ equipped with nanoflow Z-spray source (Micromass). Data were collected and processed as described by Callaghan et al. ${ }^{27}$ and Ilag et al. ${ }^{44}$

\section{Acknowledgements}

We thank Mahon Maguire, Heather Kent, Jenny Long, Ola Zaid and Sara Lejon for help in developing purification protocols. We thank David Clarke and staff at SRS Darebsury for help with circular dichroism and Len Packman for mass spectrometry analysis. We thank Peter Wright, Martin Moncrieffe, and David Tollervey for very constructive discussions. This work was supported by the Wellcome Trust.

\section{References}

1. Ehretsmann, C. P., Carpousis, A. J. \& Krisch, H. M. (1992). Specificity of Escherichia coli endoribonuclease RNase E: in vivo and in vitro analysis of mutants in a bacteriophage T4 mRNA processing site. Genes Dev. 6, 149-159.

2. Ono, M. \& Kuwano, M. (1979). A conditional lethal mutation in an Escherichia coli strain with a longer chemical half life of mRNA. J. Mol. Biol. 129, 343-357.

3. Jain, C., Deana, A. \& Balasco, J. G. (2002). Consequence of RNase E scarcity in Escherichia coli. Mol. Microbiol. 43, 1053-1064.

4. Huang, H., Liao, J. \& Cohen, S. N. (1998). Poly(A)and poly(U)-specific RNA $3^{\prime}$ tail shortening by E. coli ribonuclease E. Nature, 391, 99-102.

5. Kushner, S. R. (2002). mRNA decay in Escherichia coli comes of age. J. Bacteriol. 184, 4658-4665.

6. Ow, M. C. \& Kushner, S. R. (2002). Initiation of tRNA maturation by RNase $\mathrm{E}$ is essential for cell viability in E. coli. Genes Dev. 16, 1102-1115.

7. Steege, D. A. (2000). Emerging features of mRNA decay in bacteria. RNA, 6, 1079-1090.

8. Lee, K., Bernstein, J. A. \& Cohen, S. N. (2002). RNase $\mathrm{G}$ complementation of rne null mutation identifies functional interrelationships with RNase E in Escherichia coli. Mol. Microbiol. 43, 1445-1456.

9. Jain, C. \& Belasco, J. G. (1995). RNase E autoregulates its synthesis by controlling the degradation of its own mRNA in Escherichia coli: unusual sensitivity of the rne transcript to RNase E activity. Genes Dev. 9, 84-96.

10. Diwa, A. A. \& Belasco, J. G. (2002). Critical features of a conserved RNA stem-loop important for feedback regulation of RNase E synthesis. J. Biol. Chem. 277, 20415-20422.

11. Massé, E., Escorcia, F. E. \& Gottesman, S. (2003). Coupled degradation of a small regulatory RNA and its mRNA targets in Escherichia coli. Genes Dev. 17, 2374-2383.

12. Claverie-Martin, F., Diaz-Torres, M. R., Yancey, S. D. 
\& Kushner, S. R. (1991). Analysis of the altered mRNA stability (ams) gene from Escherichia coli. Nucleotide sequence, transcriptional analysis, and homology of its product to MRP3, a mitochondrial ribosomal protein from Neurospora crassa. J. Biol. Chem. 266, 2843-2851.

13. Casaregola, S., Jacq, A., Laoudj, D., McGurk, G., Margarson, S., Tempete, M. et al. (1992). Cloning and analysis of the entire Escherichia coli ams gene. Ams is identical to $h m p 1$ and encodes a $114 \mathrm{kDa}$ protein that migrates as a $180 \mathrm{kDa}$ protein. J. Mol. Biol. 228, $30-40$.

14. Lopez, P. J., Marchand, I., Joyce, S. A. \& Dreyfus, M. (1999). The C-terminal half of RNase E, which organises the Escherichia coli degradosome, participates in mRNA degradation but not rRNA processing in vivo. Mol. Microbiol. 33, 188-199.

15. Cohen, S. N. \& McDowall, K. J. (1997). RNase E: still a wonderfully mysterious enzyme. Mol. Microbiol. 23, 1099-1106.

16. Wachi, M., Umitsuki, G., Shimitzu, M., Takada, A. \& Nagai, K. (1999). Escherichia coli cafA gene encodes a novel RNase, designated as RNase G, involved in processing of the $5^{\prime}$ end of $16 \mathrm{~S}$ rRNA. Biochem. Biophys. Res. Commun. 259, 483-488.

17. Kaberdin, V. R., Miczak, A., Jakobsen, J. S., Lin-Chao, S., McDowall, K. J. \& von Gabain, A. (1998). The endoribonucleolytic N-terminal half of Escherichia coli RNase E is evolutionarily conserved in Synechocystis sp. and other bacteria, but not the C-terminal half, which is sufficient for degradosome assembly. Proc. Natl Acad. Sci. USA, 95, 11637-11642.

18. McDowall, K. J. \& Cohen, S. N. (1996). The N-terminal domain of the rne gene product has RNase E activity and is non-overlapping with the argininerich RNA-binding site. J. Mol. Biol. 255, 349-355.

19. Vanzo, N. F., Li, Y. S., Py, B., Blum, E., Higgins, C. F., Raynal, L. C. et al. (1998). Ribonuclease E organises the protein interactions in the Escherichia coli RNA degradosome. Genes Dev. 12, 2770-2781.

20. Diwa, A. A., Jiang, X., Schapira, M. \& Belasco, J. G. (2002). Two distinct regions on the surface of an RNA-binding domain are crucial for RNase E function. Mol. Microbiol. 46, 959-969.

21. Carpousis, A. J., Van Houwe, G., Ehretsmann, C. \& Krisch, H. M. (1994). Copurification of E. coli RNase $\mathrm{E}$ and PNPase: evidence for a specific association between two enzymes important in RNA processing and degradation. Cell, 76, 889-900.

22. Py, B., Higgins, C. F., Krisch, H. M. \& Carpousis, A. J. (1996). A DEAD-box RNA helicase in the Escherichia coli RNA degradosome. Nature, 381, 169-172.

23. Miczak, A., Kaberdin, V. R., Wei, C. L. \& Lin-Chao, S (1996). Proteins associated with the RNase E in a multicomponent ribonucleolytic complex. Proc. Natl Acad. Sci. USA, 93, 3865-3869.

24. Py, B., Causton, H., Mudd, E. A. \& Higgins, C. F. (1994). A protein complex mediating mRNA degradation in Escherichia coli. Mol. Microbiol. 14, 717-729.

25. Blum, E., Py, B., Carpousis, A. J. \& Higgins, C. F. (1997). Polyphosphate kinase is a component of the Escherichia coli RNA degradosome. Mol. Microbiol. 387, 398.

26. Wootton, J. C. (1994). Non-globular domains in protein sequences: automated segmentation using complexity measures. Comput. Chem. 18, 269-285.

27. Callaghan, A. J., Grossmann, J. G., Redko, Y. U., Ilag, L. L., Moncrieffe, M. C., Symmons, M. F. et al. (2003). Quarternary structure and catalytic activity of the
Escherichia coli ribonuclease E amino-terminal catalytic domain. Biochemistry, 42, 13848-13855.

28. Glatter, O. \& Kratzy, O. (1980). Small Angle X-ray Scattering, Academic Press, London, UK.

29. Longhi, S., Receveur-Brechot, V., Karlin, D., Johansson, K., Darbon, H. \& Yeo, R. (2003). The C-terminal domain of measles virus nucleoprotein is intrinsically disordered and folds upon binding to the Cterminal moiety of the phosphoprotein. J. Biol. Chem. 278, 18628-18648.

30. Cantor, C. R. \& Schimmel, P. R. (1980). Biophysical Chemistry Part III, WH Freeman and Company, New York.

31. Perez, J., Vachette, P., Russo, D., Desmadril, M. \& Durand, D. (2001). Heat-induced unfolding of neocarzinostatin, a small all-beta protein investigated by small-angle X-ray scattering. J. Mol. Biol. 308, $721-743$.

32. Linding, R., Russell, R. B., Neduva, V. \& Gibson, T. J. (2003). GlobPlot: exploring protein sequences for globularity and disorder. Nucl. Acids Res. 31, 3701-3708.

33. Garner, E., Guilliot, S., Dunker, A. K., Romero, P. \& Obradovic, Z. (1998). Predicting long disordered regions in protein from amino acid sequence. Biophys. J. 74, A1-A452.

34. Li, X., Romero, P., Rani, M., Dunker, A. K. \& Obradovic, Z. (1999). Predicting protein disorder for N-, Cand internal regions. Genome Inform. 10, 30-40.

35. Li, X., Obradovic, Z., Brown, C. J., Garner, E. C. \& Dunker, A. K. (2000). Comparing predictors of disordered protein. Genome Inform. 11, 172-184.

36. Dunker, A. K., Lawson, J. D., Brown, C. J., Williams, R. M., Romero, P. \& Oh, J. S. (2001). Intrinsically disordered protein. J. Mol. Graph. Model. 19, 26-59.

37. Romero, P., Obradovic, Z., Li, X., Garner, E., Brown, C. \& Dunker, A. K. (2001). Sequence complexity of disordered protein. Proteins: Struct. Funct. Genet. 42, $38-48$.

38. Lupas, A., Van Dyke, M. \& Stock, J. (1991). Predicting coiled coils from protein sequences. Science, 252, $1162-1164$.

39. Taraseviciene, L., Bjork, G. R. \& Bernt, E. U. (1995). Evidence for an RNA binding region in Escherichia coli processing endoribonuclease RNase E. J. Biol. Chem. 270, 26391-26398.

40. Hanson, C. L. \& Robinson, C. V. (2004). Proteinnucleic acid interactions-the expanding role of mass spectrometry (MS). J. Biol. Chem. 279, 24907-24910.

41. Spring, T. G. \& Wold, F. (1975). Enolase from Escherichia coli. Methods Enzymol. 42, 323-329.

42. Kühnel, K. \& Luisi, B. F. (2001). Crystal structure of the Escherichia coli RNA degradosome component enolase. J. Mol. Biol. 313, 583-592.

43. Symmons, M. F., Jones, G. H. \& Luisi, B. F. (2000). A duplicate fold is the structural basis for polynucleotide phosphorylase catalytic activity, processivity, and regulation. Struct. Fold Des. 8, 1215-1226.

44. Ilag, L. L., Westblade, L. F., Deshayes, C., Kolb, A., Busby, J. W. \& Robinson, C. V. (2004). Mass spectrometry of Escherichia coli RNA polymerase: interactions of the core enzyme with $\sigma^{70}$ and Rsd protein. Structure, 12, 269-275.

45. Kaberdin, V. R., Walsh, A. P., Jakobsen, T., McDowall, K. J. \& von Gabain, A. (2000). Enhanced cleavage of RNA mediated by an interaction between substrate and arginine rich domain of E. coli ribonuclease E. J. Mol. Biol. 301, 257-264.

46. Leroy, A., Vanzo, N. F., Sousa, S., Dreyfus, M. \& 
Carpoussis, A. J. (2002). Function in Escherichia coli of the non-catalytic part of RNase E: role in the degradation of ribosome-free mRNA. Mol. Microbiol. 45, 1231-1243.

47. Biou, V., Yaremchuk, A., Tukalo, M. \& Cusack, S. (1994). The $2.9 \AA$ crystal structure of T. thermophilus seryl-tRNA synthetase complexed with tRNA ${ }^{\text {Ser }}$. Science, 263, 1404-1410.

48. Liou, G.-G., Chang, H-Y., Lin, C.-S. \& Lin-Chao, S. (2002). DEAD box Rh1B RNA helicase physically associates with exoribonuclease PNPase to degrade double-stranded RNA independent of the degradosome assembly. J. Biol. Chem. 277, 41157-41162.

49. Carpousis, A. J. (2002). The Escherichia coli RNA degradosome: structure, function and relationship to other ribonucleotic multienzyme complexes. Biochem. Soc. Trans. 30, 150-155.

50. Jäger, S., Fuhrmann, O., Heck, C., Hebermehl, M., Schiltz, E., Rauhut, R. \& Klug, G. (2001). An mRNA degrading complex in Rhodobacter capsulatus. Nucl. Acids Res. 29, 4581-4588.

51. Lee, K. \& Cohen, S. N. (2003). A Streptomyces coelicolor functional orthologue of Escherichia coli RNase E shows shuffling of catalytic and PNPase-binding domains. Mol. Microbiol. 48, 349-360.
52. Rauhut, R. \& Klug, G. (1999). mRNA degradation in bacteria. FEMS Microbiol. Rev. 23, 353-370.

53. Kido, M., Yamanaka, K., Mitani, T., Niki, H., Ogura, T. \& Hiraga, S. (1996). RNase E polypeptides lacking a carboxy-terminal half suppress a mukB mutation in Escherichia coli. J. Bacteriol. 178, 1925-3917.

54. Bernstein, J. A., Lin, P., Cohen, S. N. \& Lin-Chao, S. (2004). Global analysis of Escherichia coli RNA degradosome function using DNA microarrays. Proc. Natl Acad. Sci. USA, 101, 2758-2763.

55. Aurikko, J.P., (2003) Structural studies of the C-terminal domain of RNase E: a scaffold for the Escherichia coli degradosome. M.Phil. thesis, University of Cambridge.

56. Semenyuk, A. V. \& Svergun, D. I. (1991). GNOM-a program package for small-angle scattering data processing. J. Appl. Crystallog. 22, 537-540.

57. Sobott, F., Hernandez, H., McCammon, M. G., Tito, M. A. \& Robinson, C. V. (2002). A tandem mass spectrometer for improved transmission and analysis of large macromolecular assemblies. Anal. Chem. 74, 1402-1407.

58. Goodstadt, L. \& Ponting, C. P. (2001). CHROMA: consensus-based colouring of multiple alignments for publication. Bioinform. Appl. Note, 17, 845-846.

Edited by P. Wright

(Received 22 December 2003; received in revised form 21 May 2004; accepted 21 May 2004) 